\title{
Paraesophageal hernia repair in elderly patients: outcomes from a 10-year retrospective study
}

\author{
Michael A. D’Elia, MD, PhD \\ Negar Ahmadi, MD* \\ Amer Jarrar, MD* \\ Amy Neville, MD \\ Joseph Mamazza, MD
}

*These authors contributed equally to this work.

Accepted Mar. 8, 2021

\author{
Correspondence to: \\ J. Mamazza \\ The Ottawa Hospital - Civic Campus \\ 737 Parkdale Avenue \\ Ottawa ON K1Y 4E9 \\ jmamazza@toh.ca
}

Cite as: Can J Surg 2022 February 17; 65(1). doi: $10.1503 /$ cjs. 017920
Background: Laparoscopic surgery has become the preferred management for paraesophageal hernias (PEH); however surgical management versus watchful waiting remains controversial in older patients.

Methods: This retrospective study analyzed the outcomes of $\mathrm{PEH}$ repair in elderly patients surgically managed at The Ottawa Hospital over a 10-year period. Patients older than 60 years who underwent $\mathrm{PEH}$ repair were examined with respect to presentation, technique and associated complications.

Results: Despite similar demographics, our study groups showed significantly different characteristics of surgical techniques. Most surgeries were performed laparoscopically; however, patients aged 70 years or older underwent more open and emergency surgeries than the younger group. Despite a 30-day postoperative complication rate of $45 \%$ and $13 \%$ in the older ( $\geq 70 \mathrm{yr}$ ) and younger (60-69 yr) groups, respectively, the rates during elective repair were similar. There were no deaths in the younger group, whereas the 30 -day mortality rate was $5 \%$ in patients aged 70 years and older, including a 2 -fold increase with emergency repair ( 4 v. 2 patients).

Conclusion: Management of $\mathrm{PEH}$ in older adults remains controversial in relation to a surgical versus watchful waiting approach. We found that in patients aged 70 years and older who undergo surgical management of $\mathrm{PEH}$ experience more open and emergency procedures, which are associated with higher complication rates. However, in the elective setting older patients had increased laparoscopic repairs and comparable complication rates to younger patients. We found the greatest outcomes with early, elective laparoscopic repair, irrespective of age.

Contexte : La chirurgie laparoscopique est devenue la modalité préférée pour les hernies paraœsophagiennes (HPO); par contre, chez les patients plus âgés, la prise en charge chirurgicale plutôt qu'une attente vigilante ne fait pas l'unanimité.

Méthodes : Cette étude rétrospective a analysé les résultats des réparations d'HPO chez des patients âgés qui ont été opérés à l'Hôpital d'Ottawa sur une période de 10 ans. Les patients de plus de 60 ans soumis à une réparation d'HPO ont été analysés au plan des symptômes, des techniques chirurgicales et des complications associées.

Résultats : Malgré des caractéristiques démographiques similaires, les groupes de notre étude se sont révélés très différents au plan des techniques chirurgicales. La plupart des chirurgies ont été effectuées par voie laparoscopique; par contre, les patients de 70 ans ou plus ont subi davantage de chirurgies ouvertes et de chirurgies d'urgence, comparativement au groupe plus jeune. Malgré un taux de complications postopératoires à 30 jours de $45 \%$ et de $13 \%$ chez les groupes âgés ( $\geq 70$ ans) et plus jeunes (60-69 ans) respectivement, pour les interventions non urgentes les taux ont été similaires. On n'a signalé aucun décès dans le groupe plus jeune, tandis que le taux de mortalité à 30 jours a été de $5 \%$ chez les patients de 70 ans et plus, y compris une augmentation du double lors des interventions urgentes (4 c. 2 patients).

Conclusion : Pour la prise en charge de l'HPO chez les adultes âgés, on ne s'entend pas sur la conduite à tenir entre l'approche chirurgicale et l'approche attentiste. Nous avons constaté que chez les patients de 70 ans et plus qui subissent une réparation chirurgicale d'HPO et il y a plus d'interventions ouvertes et d'urgence, qui sont associées à des taux de complications plus élevés. Toutefois, dans le contexte des chirurgies non urgentes, les patients âgés ont eu un plus grand nombre de réparations laparoscopiques et un taux de complications comparable à ceux des patients plus jeunes. Nous avons constaté que les résultats étaient plus favorables lors des réparations laparoscopiques précoces, non urgentes, indépendamment de l'âge. 


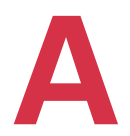

paraesophageal hernia $(\mathrm{PEH})$ refers to a subtype of hiatal hernia where a true hernia sac composed of peritoneum is formed. These are classified into 3 subtypes, types II, III and IV. A type II hiatal hernia is characterized by upward displacement of the gastric fundus alongside a normally positioned gastroesophageal (GE) junction. In type III and IV hernias, the GE junction is found above the diaphragm, with type III involving the stomach and type IV involving a second organ. ${ }^{1}$ About $5 \%-15 \%$ of all hiatal hernias are PEHs. The median age at presentation has been reported to be 65-75 years. ${ }^{2}$ Although the majority of patients with PEH are asymptomatic, some may present with epigastric or substernal pain, postprandial fullness, nausea, retching, early satiety and anemia. ${ }^{3,4}$ When left untreated, serious complications, including gastric volvulus, incarceration, gastric outlet obstruction, hemorrhage or severe intractable anemia, may occur.

Traditionally, all patients presenting with $\mathrm{PEH}$ were recommended for surgical repair to prevent complications. Before the era of laparoscopic surgery, all PEHs were repaired through a laparotomy or thoracotomy approach. After the introduction of laparoscopic PEH repair, many studies assessed the morbidity and mortality of elective laparoscopic repair, reporting varying results. ${ }^{5-8}$ In 1997, a comprehensive nationwide study in the United States reported the mortality associated with elective laparoscopic $\mathrm{PEH}$ repair to be $1.4 \%$ higher than the annual probability of requiring emergency repair of $1.1 \%{ }^{9}$ Despite quite a small difference, the concept of watchful waiting emerged as an accepted management for asymptomatic patients with $\mathrm{PEH}$. Aside from this, the symptoms of PEH can be quite vague and difficult to attribute specifically to a $\mathrm{PEH}$, and the true proportion of asymptomatic patients remains unknown.

With an aging population, concerns have been raised regarding an increased morbidity and mortality of emergency surgery in elderly patients with known PEHs. A recent nationwide study of all cases of $\mathrm{PEH}$, using the American College of Surgeons National Surgical Quality Improvement Program (NSQIP) from 2005-2012, reported a 9-fold increase in the risk of death and a 5 -fold increase in the risk of morbidity associated with an emergency repair. ${ }^{10}$ Patients requiring emergency surgery were older and had multiple medical comorbidities. The authors concluded that elective laparoscopic repair was associated with very low morbidity $(0.65 \%)$ and should be recommended to younger patients with $\mathrm{PEH}$.

Many groups continue to practise a watchful waiting strategy for elderly patients with asymptomatic PEHs, but this is certainly not without controversy. ${ }^{11}$ As a result, we planned, to our knowledge, the first Canadian study investigating surgical management of $\mathrm{PEH}$ in this population. We assessed the differences in outcomes in 2 groups of elderly patients undergoing emergency versus elective $\mathrm{PEH}$ repair.

\section{Methods}

This retrospective study was conducted in the Department of Surgery of a tertiary care hospital in Canada on patients admitted with PEH between 2004 and 2014. The medical records of all patients aged 60 years and older who underwent PEH repair at The Ottawa Hospital $(\mathrm{TOH})$ were retrieved and examined. In total, 11 different surgeons (5 general surgeons and 6 thoracic surgeons) performed these surgeries. The Ottawa Hospital Research Ethics Board approval was obtained for the study.

Data relating to demographic characteristics (age, sex, body mass index [BMI], comorbidities, American Society of Anesthesiologists [ASA] classification), presenting complaints, examination findings, surgical technique used for repair, complications and short-term outcomes during the 1-year follow-up period were collected and analyzed. Investigations, including imaging, endoscopy, and manometry, were performed in nearly all patients who underwent elective PEH repair. The operative notes were used to collect data on operative time, intraoperative findings, surgical techniques, and intraoperative complications. Postoperative and follow-up notes were examined to identify immediate and late complications, the persistence or recurrence of the symptoms, and any follow-up radiological studies. Complications were classified according to the Clavien-Dindo system. ${ }^{12}$ We particularly focused on complicaitons that were classified as grade III or higher owing to their expected greater impact to the patient.

For data analysis, we stratified patients into 2 groups based on their age: group 1 included patients aged 60-69 years, and group 2 included those aged 70 years and older. In each group, patients were further subdivided based on the surgical procedure performed (i.e., laparotomy, laparoscopy, or thoracotomy). We also stratified based on elective versus emergency repair.

\section{Statistical analysis}

Statistical analysis was performed using STATA software v.14. Summary data are presented as mean \pm standard deviation or frequency (number of patients or \% of the population). We performed $\chi^{2}$ or Fisher exact tests for the categorical variables. Parametric and nonparametric methods were used for the analysis depending on the distribution of the data (i.e., normal v. non-normal distributions). Logistic regression analysis was used to determine the association between postoperative complications and surgical technique. Statistical significance was set at a $p$ value of $<0.05$.

\section{Results}

A total of 192 patients were included in this study: 71 patients between 60 and 69 years of age and 121 
aged 70 years or older. Table 1 summarizes the demographic characteristics of the 2 groups. Overall, $63 \%$ of the procedures were performed in patients aged 70 years or older. Except for age, the 2 groups were statistically similar with respect to demographic characteristics, including sex, BMI and ASA classification. The number of repairs performed emergently varied significantly between the 2 groups, with the older group presenting significantly more emergently $(p=0.002)$.

Patients with $\mathrm{PEH}$ can present with a variety and multitude of symptoms. Figure 1 highlights the symptoms associated with our entire population and the rates of presentation. As shown, there was no significant difference between 2 groups for any individual symptom. The 2 most common presenting complaints, across all ages, were chest pain and heartburn. Table 2 shows the distribution of the $\mathrm{PEH}$ classification within the 2 groups. In each group, the majority (75\%) of individuals presented with type III PEH, with type IV and type II PEHs present to a lesser extent. There was no significant difference between the 2 groups with respect to the

\begin{tabular}{|c|c|c|c|}
\hline Characteristic & $60-69$ yr & $\geq 70 \mathrm{yr}$ & $p$ value \\
\hline No (\%) of patients & 71 (37) & $121(63)$ & - \\
\hline Age (mean $\pm S D)$, yr & $65 \pm 3$ & $77 \pm 5$ & - \\
\hline No. (\%) female & $52(73)$ & $89(74)$ & 0.96 \\
\hline $\mathrm{BMI}($ mean $\pm \mathrm{SD}), \mathrm{kg} / \mathrm{m}^{2}$ & $29 \pm 8$ & $26 \pm 7$ & 0.06 \\
\hline $\begin{array}{l}\text { ASA classification } \\
(\text { mean } \pm \text { SD) }\end{array}$ & $2.7 \pm 0.66$ & $2.9 \pm 0.85$ & 0.12 \\
\hline $\begin{array}{l}\% \text { of patients with } \\
\text { ASA classification } \\
\geq \text { grade III }\end{array}$ & 65 & 68 & 0.24 \\
\hline $\begin{array}{l}\text { No. }(\%) \text { of patients with } \\
\text { emergent repair }(\%)\end{array}$ & $5(7)$ & $28(23)$ & $<0.05$ \\
\hline
\end{tabular}

type of hernia $(p=0.202,0.931$ and 0.318 for type II, type III and type IV, respectively).

Laparoscopic repair was the predominant repair done, accounting for $65 \%$ of all repairs. The operative approach and intraoperative events from each group are summarized in Table 3. Patients aged 70 years and older underwent significantly fewer laparoscopic repairs (58\% v. $76 \%$ ), with an obligatory increase in laparotomy. Repair via thoracotomy did not differ significantly between the 2 groups. Additionally, patients presenting emergently received significantly fewer laparoscopic surgeries than patients receiving elective surgeries $(15 \%$ v. $75 \%, p<0.001)$. In total, $17 \%$ of surgeries were performed emergently, with significantly more emergent surgeries performed in the older age group $(23 \%$ v. $7 \%, p=0.004)$.

Adjusting for emergent procedures, the deference between laparoscopic and open surgery did not differ significantly between the older and younger age groups ( $81 \%$ v. $70 \%, p=0.08)$. A similar observation was seen with respect to both gastropexy and anti-reflux procedures: the older age group underwent significantly more gastropexy procedures $(32 \%$ v. $12 \%, p=0.006)$; however, after adjusting for only elective presentation, the difference was no longer significant $(p=0.19)$. With respect to anti-reflux procedures (Nissen, Toupet, Dor, BelseyMark IV), $77 \%(n=138)$ of cases involved a fundoplication, with $90 \%$ in the 60-69 age group compared with $65 \%$ in the older age group. Again, examining only elective procedures, there was no significant difference in fundoplication $(94 \%$ v. $86 \%, p=0.15)$.

Overall, length of stay (LOS) and the intraoperative complication rate were similar between the 2 groups. The overall LOS did not differ significantly between the 2 groups; however, not surprisingly, the average LOS stay was significantly longer for the patients undergoing emergency surgery than elective surgery $(27.3$ v. $7.1 \mathrm{~d}, p<0.001)$ and in those undergoing an

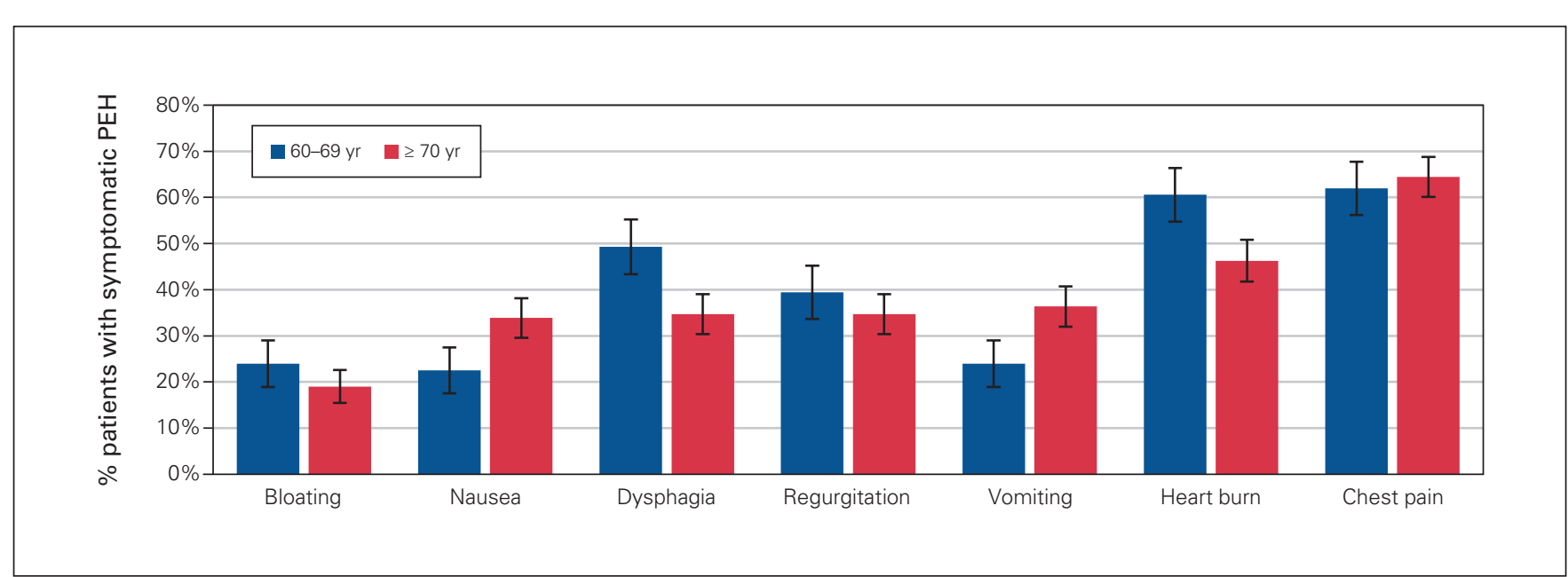

Fig. 1. Distribution of the most common presenting symptoms of patients undergoing paraesophageal hernia (PEH) repair, by age group with standard deviations. No symptom differed significantly between the groups. 
open repair compared with laparoscopic repair $(17.9$ v. $6.2 \mathrm{~d}$, $p<0.001)$. The overall postoperative complication rate was $33 \%(63 / 186)$. The complication details were not available for 3 individuals in each group; therefore, they were omitted from the calculations. Table 4 summarizes the 30 -day postoperative complication rates: $49 \%$ in patients aged 70 years and older compared with $13 \%$ in patients aged $60-69$ years $(p<0.001)$. The choice of operative technique also appeared to affect the complication rate (Table 5). Comparing only intra-abdominal approaches (laparoscopic and open), the overall complication rate was $12 \%$ and $45 \%$ in the younger and older age groups, respectively. Comparing laparoscopic to open procedures, the younger group showed a 5.88-fold (1.05-32.85) increase and the older age group a 3.06-fold (1.36-6.87) increase in overall complication rate with an open technique. When adjusting for a Clavien-Dindo classification of grade III or higher complications and comparing laparoscopic with open procedures, this finding continued to hold true: we found a a 3.06-fold (0.25-37.84) and 2.2-fold (0.84-5.78) increase in the complication rate in the younger and older populations, respectively, indicating that an open repair has a significantly increased rate of complications compared with laparoscopic repairs, irrespective of age.

\begin{tabular}{|c|c|c|}
\hline PEH type & $60-69 \mathrm{yr}, \%$ & $\geq 70 \mathrm{yr}, \%$ \\
\hline Type II & 14 & 8 \\
\hline Type III & 75 & 75 \\
\hline Type IV & 11 & 17 \\
\hline
\end{tabular}

The overall complication rate during emergency surgery was high in both the groups: $40 \%$ in the younger and $61 \%$ in the older age group $(p=0.39)$. In fact, the odds of developing a postoperative complication was much higher for emergency surgery than elective surgery. Again, adjusting for only abdominal procedures, the younger group showed a 5.33-fold (0.76-37.64) increase in complication rate, while the older group showed a 1.93 -fold (0.83-4.53) increase. Looking specifically at complications with a Clavien-Dindo classification of grade III or higher, there were only 3 postoperative complications in the 60-69 age group, and they all occurred in the elective setting. In the older age group, emergency surgery had a 4.07 -fold $(1.59,10.43)$ increase in complication compared with elective surgery.

The 30-day mortality rate for the entire population was $3.1 \%$, and all patients who died were aged 70 years or older. The mortality rate for elective repair was $1.3 \%$. Looking at surgery performed emergently, there was a 10.83-fold (1.89-61.87) increase in odds of death overall. Specifically looking at patients aged 70 years or older, the 30 -day mortality rate following elective surgery was $2.1 \%$ compared with $14 \%$ for emergency surgery $(p=0.010)$, a 7.58-fold (1.31-43.9) increase in odds of death for emergent surgery.

\section{Follow-up}

Eighty-four percent of the patients were followed up postsurgery, for a follow-up rate of $90 \%$ in the younger age group and $80 \%$ in the older age group. The mean follow-up duration for the entire population was 19 months: 24 months

Table 3. Comparison of operative techniques and intraoperative events in patients undergoing PEH repair

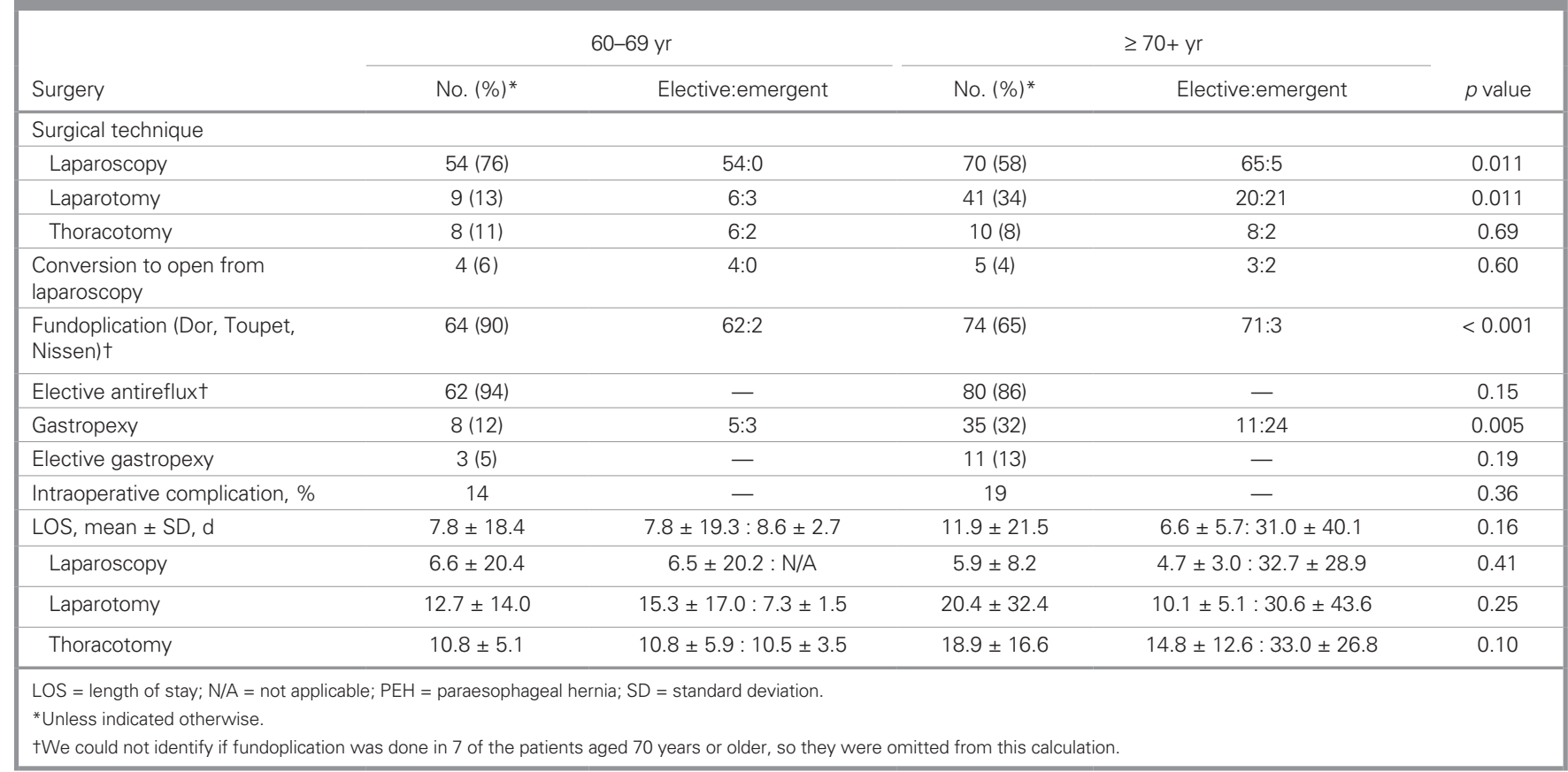




\begin{tabular}{|c|c|c|c|c|c|}
\hline \multirow[b]{2}{*}{ Complication } & \multicolumn{2}{|c|}{$60-69 \mathrm{yr}^{*}$} & \multicolumn{2}{|c|}{$\geq 70 \mathrm{yr}^{*}$} & \multirow[b]{2}{*}{$p$ value } \\
\hline & No. (\%) & Elective:emergent & No. (\%) & Elective:emergent & \\
\hline \multicolumn{6}{|c|}{ Clavien-Dindo classification } \\
\hline 1 & 0 & $0: 0$ & $7(6)$ & $7: 0$ & N/A \\
\hline$\|$ & $6(9)$ & $4: 2$ & $23(19)$ & $18: 5$ & 0.023 \\
\hline $\mathrm{IIlb}$ & $1(1.5)$ & $1: 0$ & $14(12)$ & $11: 3$ & 0.012 \\
\hline $\mathrm{IVa}$ & $2(3)$ & $2: 0$ & $8(7)$ & $3: 5$ & 0.43 \\
\hline$V$ (death) & 0 & $0: 0$ & $6(5)$ & $2: 4$ & N/A \\
\hline \multicolumn{6}{|c|}{ Major postoperative complication } \\
\hline Pulmonary & $4(6)$ & $4: 0$ & $19(16)$ & $12: 7$ & 0.019 \\
\hline Cardiac & $2(3)$ & $1: 1$ & $13(13)$ & $10: 3$ & 0.050 \\
\hline Leak & $3(4)$ & $3: 0$ & $6(5)$ & $5: 1$ & 0.80 \\
\hline Abscess & $2(3)$ & $2: 0$ & $6(5)$ & $2: 4$ & 0.50 \\
\hline Dysphagia & 0 & 0 & $6(5)$ & $5: 1$ & $<0.001$ \\
\hline SSI & $4(6)$ & $3: 1$ & $8(11)$ & $5: 3$ & 0.81 \\
\hline
\end{tabular}

Table 5. Clavien-Dindo grade III-V postoperative complications in patients undergoing PEH repair, by procedure type

\begin{tabular}{|c|c|c|c|}
\hline Procedure type & $60-69$ yr, no. (\%) & $\geq 70 \mathrm{yr}$, no. $(\%)$ & $p$ value \\
\hline \multicolumn{4}{|l|}{ Laparoscopic } \\
\hline Overall & 2/51 (4) & 10/68 (15) & 0.05 \\
\hline Elective & $2 / 51$ (4) & $7 / 63(11)$ & 0.16 \\
\hline Emergent & 0 & 3/5 (60) & N/A \\
\hline \multicolumn{4}{|l|}{ Open } \\
\hline Overall & 1/9 (11) & $11 / 40$ (27) & 0.30 \\
\hline Elective & $1 / 6(17)$ & 3/19 (16) & 0.96 \\
\hline Emergent & 0 & 8/21 (39) & N/A \\
\hline \multicolumn{4}{|l|}{ Overall } \\
\hline Overall & 3/60 (5) & 21/108 (19) & 0.010 \\
\hline Elective & 3/57 (5) & 10/82 (12) & 0.17 \\
\hline Emergent & 0 & 11/26 (42) & N/A \\
\hline
\end{tabular}

for the younger age group and 16 months for the older age group. Among patients with routine postoperative follow-up, $72 \%$ became completely asymptomatic postoperatively. The proportion of symptomatic patients did not differ significantly among the 2 groups. The most common postoperative symptom was dysphagia (14\%), followed by heartburn (7\%), regurgitation (7\%), postprandial bloating (7\%) and flatulence $(5 \%)$. There was no significant difference between the distributions of these symptoms among the 2 groups. Most patients with symptoms underwent postoperative imaging (upper gastrointestinal series) and, of those, 50\% had a radiologically confirmed anatomic recurrence.

\section{Discussion}

For decades, the management of PEHs was surgical intervention at diagnosis, given the potential for acute gastric volvulus and ischemia. With the emergence of laparoscopic surgery, laparoscopic repair of PEHs has been increasingly used, as many studies have established it as a safe and effective approach. ${ }^{8,10,13}$ In 2002, Stylopoulos and colleagues ${ }^{14}$ examined the clinical outcomes associated with 2 management strategies for $\mathrm{PEH}$ in patients older than 65 years who were asymptomatic or minimally symptomatic, comparing elective laparoscopic hernia repair (ELHR) to watchful waiting. They concluded that watchful waiting was a better initial strategy in $83 \%$ of patients. Additionally, they reported that the risk of developing acute symptoms decreased with increasing age; yet, the risk could be as high as $18 \%$ in patients aged 65 years and older. ${ }^{14}$ Additionally, Molena and colleagues, ${ }^{15}$ using an NSQIP database analysis of benign foregut disease, showed an overall significantly higher 30-day morbidity and mortality following elective repair among patients older than 70 years. However, their study was not limited to PEH repair and examined all benign foregut diseases. With these results, watchful waiting in a population older than 65 years remains a widely acceptable and common management option.

The obvious concern with a watchful waiting strategy the possibility of catastrophic complications, such as gastric volvulus, prompting emergent management. ${ }^{16}$ As expected, and as shown with our data, emergency presentation leads to significantly increased rate of an open (laparotomy) procedure and ultimately increased morbidity and mortality. Contrary to previous studies, a study by Morrow and colleagues ${ }^{17}$ found that ELHR was superior to watchful waiting in terms of quality of life for minimally symptomatic PEHs. ${ }^{17}$ Additionally, a recent meta-analysis looking specifically at octogenarians showed that elective $\mathrm{PEH}$ repair can be safely performed with improved symptoms and minimal morbidity, including the safety associated with laparoscopy in this group. ${ }^{18}$ 
The management of PEHs, particularly in elderly patients, remains a complex problem with conflicting management goals. Using a retrospective cohort study comparing 2 elderly populations, we showed that elective repair in the older age group provides benefit as it limits the potential for emergency and open approaches, which both contribute to significantly greater morbidity.

The definition of "elderly" with respect to repair of PEH has been reported as 70 years and older in many studies. ${ }^{15,19,20}$ Here, we examined similar cohorts of patients with $\mathrm{PEH}$ who were 70 years and older and compared them to patients aged 60-69 years. We showed that our older population underwent significantly more open and emergent procedures. Subanalysis of this group identified that both open and emergency procedures were independently related to increased complications, suggesting that limiting both can minimize negative outcomes.

The rate of laparoscopic repair in our study was $65 \%$, which is slightly lower than previously reported rates. ${ }^{13,20}$ This rate may be institutional, as procedures at our institution are performed by a diverse group of 11 surgeons in 2 specialties, with $75 \%$ of the repairs being performed by 5 surgeons. Despite the number of surgeons, our data do not show any significant difference between the group of 5 surgeons and the remainder in relation to operative technique (laparoscopic v. open) or complication rate.

Given the higher numbers of the emergency repairs for complicated PEH in patients aged 70 years or older, the laparoscopic rate in this group was only $58 \%$, likely owing to a desire to minimize operative time or to concerns regarding tolerance of insufflation. In our analysis of open versus laparoscopic repairs, even in the elective setting open procedures were associated with a more than 2 -fold increased number of postoperative complications. Again, this highlights the importance of minimizing complications with a laparoscopic approach.

Our overall rate of emergent repair was $17 \%$ (23\% in patients aged 70 years and older, and $7 \%$ in those aged 60-69 years). Previous studies reported wide-ranging rates of emergency $\mathrm{PEH}$ repair, from $3.6 \%$ in the NSQIP registry ${ }^{10,15}$ to $24.6 \%$ in a large multicentre study. ${ }^{13}$ Despite a wide range, our emergent repair rates fall in line with previously published literature. Our data support the notion that elective repair is favoured to emergent repair with respect to postoperative complications, particularly in the older age group (Table 5). Furthermore, our outcomes were best with laparoscopic procedures. Limiting our assessment to complications with a Clavien-Dindo classification of graded III or higher and excluding more minor complications, such as urinary tract infections, that tend to be more prevalent in older individuals, there was a clear trend showing significantly increased complication rates with emergent procedures. Although our statistical analysis was limited by the small number of emergent procedures in the 60-69 age group, there were significantly more complications in the emergent group. Interestingly, this statistical difference disappeared when examining only elective procedures. For elective procedures, our data showed similar postoperative complication rates for elective $\mathrm{PEH}$ repair in both groups. Our results were significantly more alarming when we specifically examined the mortality rate (Clavien-Dindo classification of grade V). Deaths were limited to patients aged 70 years and older, which revealed a 7 -fold increase with emergency compared with elective repair (15\% v. $2.4 \%)$, which is consistent with previously reported results. ${ }^{10}$ This information provides strong support for the outcome benefits associated with elective repair in older patients, where the outcomes are on par with those in the 60-69 age group.

With this study, we have identified significantly higher morbidity and mortality rates associated with emergent PEH repair, with additional benefits shown with laparoscopic repair. This study shows that within the elective setting the complication rates between the 2 age groups are statistically similar, but in the emergent setting, the older age group shows not only increased morbidity, but also increased mortality. Furthermore, there was a trend toward a benefit with laparoscopic surgery over an open technique. Additionally, this study and others have shown a clear benefit with respect to pain and LOS with laparascopic surgery, making this technique the gold standard for PEH repair (Table 3). ${ }^{21,22}$ Therefore, the associated benefits from elective repair, combined with the morbidity associated with emergent repair, particularly in the older age group, argue for laparoscopic management of $\mathrm{PEH}$ at the time of presentation, irrespective of age.

\section{Limitations}

Here we provided a strong argument for the elective surgical management of PEHs. Our study was limited in the exploration of truly asymptomatic individuals. Of all our study patients, we could not identify specific symptoms in only 14 patients in both groups. Unfortunately, we cannot comment on the degree of symptomatology of the others, and therefore cannot determine how many were minimally symptomatic. Additionally, as our cohort included only individuals who underwent surgery, we cannot comment on the usefulness of a watchful waiting approach in this specific group; however, we were able to show the benefit of elective repair even in patients aged 70 years and older. The degree to which a watchful waiting population would become symptomatic and necessitate surgery as well as who among them would be suitable for an elective repair is difficult to appreciate. As we have highlighted here, the ultimate presentation would be the greatest contributor to a successful outcome. 


\section{Conclusion}

The management of PEH repair has changed considerably over the years. The best management strategy of older individuals ( $\geq 65$ years) remains controversial, with some groups using a watchful waiting approach for asymptomatic and minimally symptomatic patients. The risk associated with watchful waiting is the possibility of progression to a life-threatening complication.

Not surprisingly, we have shown that patients with $\mathrm{PEH}$ who are older than 70 years of age are more likely to require emergency repair and undergo fewer laparoscopic surgeries than younger patients. This older patient population also tends to experience significantly higher postoperative morbidity and mortality. However, we have shown that this cohort of patients benefits most from having an elective repair and that, in this setting, complication rates are on par with those in a younger cohort. Support for early, elective repair is further strengthened with examination of mortality. In our study, deaths occurred only in patients older than 70 years, with at least a 7 -fold decrease in mortality observed with elective repair. With advances in less-invasive, laparoscopic surgical techniques, outcomes from gastrointestinal surgery have improved for all age groups, and based on our findings we believe that patients may benefit from elective laparoscopic repair at a younger age. This strengthens the notion for lowering the threshold for $\mathrm{PEH}$ repair, irrespective of age.

Affiliations: From the Department of Surgery, University of Ottawa, Ottawa, Ont. (D'Elia, Jarrar, Neville, Mamazza); and the Department of Surgery, McMaster University, Hamilton, Ont. (Ahmadi).

Competing interests: None declared.

Contributors: M. D'Elia, N. Ahmadi, A. Jarrar and J. Mamazza designed the study. All authors acquired and analysed the data. M. D'Elia, A. Jarrar and J. Mamazza wrote the article, which all authors reviewed. All authors gave final approval of the article to be published.

Content licence: This is an Open Access article distributed in accordance with the terms of the Creative Commons Attribution (CC BY-NC-ND 4.0) licence, which permits use, distribution and reproduction in any medium, provided that the original publication is properly cited, the use is noncommercial (i.e., research or educational use), and no modifications or adaptations are made. See: https://creativecommons.org/licenses/by-nc-nd/4.0/

\section{References}

1. Lal DR, Pellegrini CA, Oelschlager BK. Laparoscopic repair of paraesophageal hernia. Surg Clin North Am 2005;85:105-18.

2. Hashemi M, Sillin LF, Peters JH. Current concepts in the management of paraesophageal hiatal hernia. F Clin Gastroenterol 1999;29:8-13.

3. Kahrilas PJ, Kim HC, Pandolfino JE. Approaches to the diagnosis and grading of hiatal hernia. Best Pract Res Clin Gastroenterol 2008; 22:601-16.
4. Carrott PW, Hong J, Kuppusamy M, et al. Clinical ramifications of giant paraesophageal hernias are underappreciated: making the case for routine surgical repair. Ann Thorac Surg 2012;94: 421-6.

5. Zaman JA, Lidor AO. The optimal approach to symptomatic paraesophageal hernia repair: important technical considerations. Curr Gastroenterol Rep 2016;18:53.

6. Bingener J, Buck L, Richards M, et al. Long-term outcomes in laparoscopic vs open ventral hernia repair. Arch Surg 2007;142:562-7.

7. Zehetner J, Demeester SR, Ayazi S, et al. Laparoscopic versus open repair of paraesophageal hernia: the second decade. 7 Am Coll Surg 2011; 212:813-20.

8. Mungo B, Molena D, Stem M, et al. O. Thirty-day outcomes of paraesophageal hernia repair using the NSQIP database: should laparoscopy be the standard of care? 7 Am Coll Surg 2014;219: 229-36.

9. Lebenthal A, Waterford SD, Fisichella PM. Treatment and controversies in paraesophageal hernia repair. Front Surg 2015;2:13.

10. Kaplan JA, Schecter S, Lin MY, et al. Morbidity and mortality associated with elective or emergency paraesophageal hernia repair. 7AMA Surg 2015;150:1094-6.

11. Shea B, Boyan W, Decker J, et al. Emergent repair of paraesophageal hernias and the argument for elective repair. FSLS 2019; 23:e2019.00015.

12. Dindo D, Demartines N, Clavien PA. Classification of surgical complications: a new proposal with evaluation in a cohort of 6336 patients and results of a survey. Ann Surg 2004;240:205-13.

13. Klinginsmith M, Jolley J, Lomelin D, et al. Paraesophageal hernia repair in the emergency setting: Is laparoscopy with the addition of a fundoplication the new gold standard? Surg Endosc 2016;30:1790-5.

14. Stylopoulos N, Gazelle GS, Rattner DW. Paraesophageal hernias: Operation or observation? Ann Surg 2002;236:492-500.

15. Molena D, Mungo B, Stem M, et al. O. Outcomes of operations for benign foregut disease in elderly patients: a National Surgical Quality Improvement Program database analysis. Surgery 2014;156:352-60.

16. Polomsky M, Hu R, Sepesi B, et al. A population-based analysis of emergent vs. elective hospital admissions for an intrathoracic stomach. Surg Endosc 2010;24:1250-5.

17. Morrow EH, Chen J, Patel R, et al. Watchful waiting versus elective repair for asymptomatic and minimally symptomatic paraesophageal hernias: a cost-effectiveness analysis. Am 7 Surg 2018;216:760-3.

18. Straatman J, Groen LCB, van der Wielen N, et al. Treatment of paraesophageal hiatal hernia in octogenarians: a systematic review and retrospective cohort study. Dis Esophagus 2018;31:10.

19. Hazebroek EJ, Gananadha S, Koak Y, et al. Laparoscopic paraesophageal hernia repair: quality of life outcomes in the elderly. Dis Esophagus 2008;21:737-41.

20. Louie BE, Blitz M, Farivar AS, et al. Repair of symptomatic giant paraesophageal hernias in elderly (>70 years) patients results in improved quality of life. 7 Gastrointest Surg 2011;15:389-96.

21. Willekes CL, Edoga JK, Frezza EE. Laparoscopic repair of paraesophageal hernia. Ann Surg 1997;225:31-8.

22. Latzko M, Borao F, Squillaro A, et al. Laparoscopic repair of paraesophageal henias. FSLS 2014;18. 